\title{
Differential diagnosis of granulomatous lung disease: clues and pitfalls
}

\author{
Shinichiro Ohshimo ${ }^{1}$, Josune Guzman ${ }^{2}$, Ulrich Costabel ${ }^{3}$ and \\ Francesco Bonella ${ }^{3}$
}

Number 4 in the Series "Pathology for the clinician" Edited by Peter Dorfmüller and Alberto Cavazza

\begin{abstract}
Affiliations: ${ }^{1}$ Dept of Emergency and Critical Care Medicine, Graduate School of Biomedical Sciences, Hiroshima University, Hiroshima, Japan. ${ }^{2}$ General and Experimental Pathology, Ruhr-University Bochum, Bochum, Germany. ${ }^{3}$ Interstitial and Rare Lung Disease Unit, Ruhrlandklinik, University of Duisburg-Essen, Essen, Germany.

Correspondence: Francesco Bonella, Interstitial and Rare Lung Disease Unit, Ruhrlandklinik, University of Duisburg-Essen, Tueschener Weg 40, 45239 Essen, Germany.

E-mail: francesco.bonelladruhrlandklinik.uk-essen.de
\end{abstract}

@ERSpublications

A multidisciplinary approach is crucial for the accurate differential diagnosis of granulomatous lung diseases http://ow.ly/FxsP30cebtf

Cite this article as: Ohshimo S, Guzman J, Costabel U, et al. Differential diagnosis of granulomatous lung disease: clues and pitfalls. Eur Respir Rev 2017; 26: 170012 [https://doi.org/10.1183/16000617.0012-2017].

\begin{abstract}
Granulomatous lung diseases are a heterogeneous group of disorders that have a wide spectrum of pathologies with variable clinical manifestations and outcomes. Precise clinical evaluation, laboratory testing, pulmonary function testing, radiological imaging including high-resolution computed tomography and often histopathological assessment contribute to make a confident diagnosis of granulomatous lung diseases. Differential diagnosis is challenging, and includes both infectious (mycobacteria and fungi) and noninfectious lung diseases (sarcoidosis, necrotising sarcoid granulomatosis, hypersensitivity pneumonitis, hot tub lung, berylliosis, granulomatosis with polyangiitis, eosinophilic granulomatosis with polyangiitis, rheumatoid nodules, talc granulomatosis, Langerhans cell histiocytosis and bronchocentric granulomatosis). Bronchoalveolar lavage, endobronchial ultrasound-guided transbronchial needle aspiration, transbronchial cryobiopsy, positron emission tomography and genetic evaluation are potential candidates to improve the diagnostic accuracy for granulomatous lung diseases. As granuloma alone is a nonspecific histopathological finding, the multidisciplinary approach is important for a confident diagnosis.
\end{abstract}

\begin{abstract}
Previous articles in this series: No. 1: Ghigna MR, Mooi WJ, Grünberg K. Pulmonary hypertensive vasculopathy in parenchymal lung diseases and/or hypoxia. Eur Respir Rev 2017; 26: 170003. No. 2: Bubendorf L, Lantuejoul S, de Langen AJ, et al. Nonsmall cell lung carcinoma: diagnostic difficulties in small biopsies and cytological specimens. Eur Respir Rev 2017; 26: 170007. No. 3: Rossi G, Cavazza A, Spagnolo P, et al. The role of macrophages in interstitial lung diseases. Eur Respir Rev 2017; 26: 170009.
\end{abstract}

Received: Jan 262017 | Accepted after revision: May 252017

Support statement: This study was supported by Arbeitsgemeinschaft zur Förderung der Pneumologie an der Ruhrlandklinik (AFPR) and Japan Society for the Promotion of Science (JSPS) KAKENHI Grant (number JP 16K09541). Funding information for this article has been deposited with the Crossref Funder Registry.

Conflict of interest: Disclosures can be found alongside this article at err.ersjournals.com

Provenance: Commissioned article, peer reviewed.

Copyright OERS 2017. ERR articles are open access and distributed under the terms of the Creative Commons Attribution Non-Commercial Licence 4.0. 


\section{Introduction}

The term granulomatous lung disease does not refer to a specific disease entity, but to a wide spectrum of pathologies with variable clinical manifestations and outcomes. Both infectious and noninfectious diseases can be associated with granuloma formation. Careful clinical evaluation, laboratory testing, pulmonary function testing and radiological imaging including high-resolution computed tomography (HRCT) are crucial steps in the diagnostic approach to granulomatous lung diseases. In most cases, lung biopsy with expert pathological examination of lung tissue specimens is necessary.

This review focuses on novel procedures and recent advances in the differential diagnosis of granulomatous lung diseases.

\section{Definition of granuloma}

A granuloma is a focal aggregation of inflammatory cells, activated macrophages (epithelioid histiocytes), Langhans giant cells and lymphocytes. Epithelioid histiocytes have ill-defined cell borders and elongated nuclei, which are different from the well-defined cell borders and round nuclei observed in ordinary histiocytes. The presence of necrosis, lymphocytes, plasma cells or multinucleated giant cells is not essential for granuloma formation [1]. Caseation necrosis is defined as a region in granulomas with eosinophilic, granular and cheese-like cellular debris with necrosis.

\section{Basic diagnostic procedure and difficulties}

The differential diagnoses of granulomatous lung disease are listed in table 1. As histological abnormality alone is rarely diagnostic for a specific granulomatous disorder, the diagnostic procedure should focus on precise clinical evaluation, laboratory testing, detection of infectious organisms and radiological evaluation. The small size of tissue samples obtained by transbronchial lung biopsy (TBLB), together with high interobserver variability among pathologists, complicates the interpretation of histopathology. Surgical lung biopsy can provide larger tissue samples compared with TBLB.

As infection is a common cause of pulmonary granulomas, it is always important to exclude infectious lung diseases. The most frequently found organisms in pulmonary granulomas are mycobacteria and fungi. Although infectious lung diseases can show both necrotising and nonnecrotising granulomas, necrotising granulomas are more likely to be associated with infectious lung diseases [2]. Clinicians should note that tuberculosis (TB) may also show nonnecrotising granulomas, depending on the immune status of the patient.

\section{TABLE 1 Differential diagnosis of granulomatous lung diseases}

\begin{tabular}{|c|c|}
\hline \multicolumn{2}{|l|}{ nfectious lung diseases } \\
\hline Mycobacteria & Tuberculosis and nontuberculous mycobacteriosis \\
\hline Fungal infection & Cryptococcus, Coccidioides, Histoplasma, Blastomyces and Aspergillus \\
\hline \multicolumn{2}{|l|}{ Aspiration pneumonia } \\
\hline Others & $\begin{array}{l}\text { Syphilis, Hansen's disease (leprosy), tularaemia, cat scratch disease, } \\
\text { parasitic infections and Whipple's disease }\end{array}$ \\
\hline \multicolumn{2}{|c|}{ Noninfectious lung diseases } \\
\hline \multirow[t]{4}{*}{ Inflammatory } & Sarcoidosis \\
\hline & Necrotising sarcoid granulomatosis \\
\hline & Bronchocentric granulomatosis \\
\hline & Inflammatory bowel disease \\
\hline \multirow[t]{7}{*}{ Exposure/toxins } & Hypersensitivity pneumonitis \\
\hline & $\begin{array}{l}\text { Drugs (methotrexate, interferon, Bacillus Calmette-Guérin, infliximab, } \\
\text { etanercept, leflunomide, mesalamine and sirolimus) }\end{array}$ \\
\hline & Hot tub lung \\
\hline & Berylliosis \\
\hline & Talc \\
\hline & Metals (aluminium and zirconium) \\
\hline & Foreign body reaction \\
\hline \multirow[t]{2}{*}{ Vasculitis } & Granulomatosis with polyangiitis \\
\hline & Eosinophilic granulomatosis with polyangiitis \\
\hline Autoimmune diseases & Rheumatoid nodule \\
\hline \multirow[t]{2}{*}{ Malignancy } & Sarcoid-like lesions \\
\hline & Lymphomatoid granulomatosis \\
\hline \multirow[t]{2}{*}{ Others } & Pulmonary Langerhans cell histiocytosis \\
\hline & Granulomatous-lymphocytic interstitial lung disease \\
\hline
\end{tabular}


The histochemical stains commonly used for the pathological evaluation of infective organisms are the Grocott methenamine silver (GMS) stain for fungi and the Ziehl-Neelsen stain for mycobacteria. The periodic acid-Schiff (PAS) stain is also a useful histochemical stain for fungi. The PAS stain can detect the cell walls of living fungi, whereas the GMS stain detects the cell walls of both living and dead fungal organisms [3]. Auramine-rhodamine fluorescence shows greater sensitivity than Ziehl-Neelsen staining, although specificity is lower (auramine-rhodamine: sensitivity $80 \%$ and specificity $84 \%$; Ziehl-Neelsen: sensitivity $60 \%$ and specificity $98 \%$ ) [4].

When mycobacteria are identified, the next step is to differentiate tuberculous mycobacteria from nontuberculous mycobacteria (NTM). However, tuberculous mycobacteria and NTM are morphologically similar and often undistinguishable. Currently, the only definitive methods for differentiating mycobacteria are microbiological culture and PCR. Mycobacteria can grow in culture even when specific staining yields negative results. If microbiological culture is not available, PCR is the only method for differentiating the organisms.

\section{Infectious lung diseases}

\section{Tuberculosis}

Initiation of a diagnostic evaluation for TB is usually based on a suspicion of TB from epidemiological, clinical and radiographic findings. In general, prolonged cough, lymphadenopathy, fevers, night sweats and weight loss are suggestive of TB, but are nonspecific. Typical radiological findings for TB include focal infiltration of the upper lobe(s), cavitation, tissue destruction, fibrosis with traction bronchiectasis, enlargement of hilar/mediastinal lymph nodes, small nodular lesions and pleural effusions. Detection of Mycobacterium tuberculosis in sputum, bronchoscopy specimens, gastric secretions or pleural fluid is necessary for a confident diagnosis. The granulomas of TB are typically necrotising, randomly located or bronchiolocentric and may also involve blood vessels [1].

TB-PCR using endobronchial ultrasound-guided transbronchial needle aspiration (EBUS-TBNA) samples is a novel technique in the differential diagnosis of intrathoracic granulomatous lymphadenopathy [5]. Sensitivity, specificity, positive predictive value, negative predictive value and diagnostic accuracy for $\mathrm{TB}$ were found to be $56 \%, 100 \%, 100 \%, 81 \%$ and $85 \%$, respectively [5]. Heterogeneous echotexture in the EBUS feature $(53 \%$ versus $13 \% ; \mathrm{p}<0.001)$ and coagulation necrosis signs $(26 \%$ versus $3 \% ; \mathrm{p}<0.001)$ in specimens obtained by EBUS-TBNA are suggestive of TB rather than sarcoidosis [6].

The Xpert MTB/RIF assay is a novel semi-automated hemi-nested nucleic acid amplification test that can simultaneously identify M. tuberculosis and rifampicin resistance within $2 \mathrm{~h}$ [7-10]. DHOoria et al. [11] investigated the role of Xpert MTB/RIF combined with EBUS-TBNA in differentiating TB from sarcoidosis in 147 patients with mediastinal lymphadenopathy. Xpert MTB/RIF was positive in $26(49 \%)$ patients with TB and two (2\%) patients with sarcoidosis. Xpert MTB/RIF showed good specificity (98\%) and positive predictive value (93\%) in the diagnosis of TB. Accordingly, Xpert MTB/RIF combined with EBUS-TBNA has the potential to become a novel tool to supplement smear microscopy for rapid diagnosis in patients with suspected TB.

\section{Nontuberculous mycobacteriosis}

NTM are mycobacterial species other than those belonging to the M. tuberculosis complex. More than 140 NTM species have been identified to date. NTM cause a wide range of organ involvement, with pulmonary infections being the most frequent (65-90\%) [12]. Pulmonary lesions of NTM are caused primarily by Mycobacterium avium complex (90\%) and Mycobacterium kansasii (10\%). Traditionally, NTM infection in the lung was thought to be associated with immunodeficiency or pre-existing lung disease, such as chronic obstructive pulmonary disease or cystic fibrosis. However, it is now recognised that NTM infection in the lung also occurs in immunocompetent patients without pre-existing lung disease [13]. A radiological manifestation of right middle lobe or lingular infiltrates is typical in elderly women without predisposing lung disease [14]. In immunocompromised patients, NTM infection is characterised by mycobacteria-containing foamy histiocytes, poorly formed granulomas or absence of an appropriate inflammatory response [15]. In immunocompetent patients, however, NTM infection demonstrates a wide variety of histological findings, including inflammation and both necrotising and nonnecrotising peribronchiolar granulomas [16]. The histological appearance of NTM alone is indistinguishable from that of TB. Exposure to aerosolised NTM can cause a hypersensitivity pneumonitis-like disease known as "hot tub lung" (as discussed in a later section).

\section{Fungal granuloma}

In immunocompetent patients, exposure to a small amount of fungus leads to asymptomatic infection. However, exposure to a large amount of fungus may lead to an acute flu-like or pneumonia-like disease 
(e.g. Coccidioides, Histoplasma and Blastomyces). The clinical manifestation of these infections resembles influenza or community-acquired pneumonia. Diagnosis of fungal infection is made predominantly by serological rather than histological examination [17]. Occasionally, fungal organisms persist in a well-formed, necrotising granuloma, similar to TB (e.g. Cryptococcus, Coccidioides and Histoplasma) $[18,19]$. Fungal infection occasionally progresses, resulting in chronic fungal lung disease. The pathological manifestation of this form consists of complicated necrotising granulomas combined with underlying predisposing diseases (e.g. emphysema and cavities). In immunocompromised patients, fungal infections may present as a disseminated form, with poorly formed granulomas and widespread lesions [20]. This form of disease often involves the lymphohaematopoietic system and the lungs.

\section{Noninfectious lung diseases \\ Sarcoidosis \\ General diagnostic procedure}

Sarcoidosis is a systemic granulomatous disease with a heterogeneous clinical manifestation. Although pulmonary involvement is typically predominant, other organs can also be involved and about half of patients are asymptomatic. The diagnosis of sarcoidosis can be made by fulfilling the following criteria: 1) a compatible clinical and/or radiological abnormality, 2) histological confirmation of noncaseating granulomas, and 3) exclusion of other diseases capable of presenting similar histological and clinical manifestations [21]. Typical histological findings of sarcoidosis are discrete, well-formed, interstitial nonnecrotising epithelioid cell granulomas showing a lymphangitic distribution. Lymphocyte infiltration and granulomas can be found in the pleura, interlobular septa and bronchovascular bundles. Although noncaseating or nonnecrotising granulomas are the hallmark of sarcoidosis, discrete areas of fibrinoid necrosis may be seen in the centre of some granulomas in cases of typical sarcoidosis. This type of necrosis is distinguishable from caseation by the persistence of an intact reticulin pattern, as shown by silver staining. The incidence of fibrinoid necrosis in sarcoidosis ranges from $6 \%$ to $35 \%$ [22-25], and may be associated with prominent systemic symptoms (e.g. fever, erythema nodosum and arthralgia) and recent onset of sarcoidosis. The lung tissue apart from the granulomas in sarcoidosis is normal, while hypersensitivity pneumonitis shows significant interstitial inflammation even in areas apart from granulomas. Granulomatous vasculitis may also be seen in sarcoidosis, which is not observed in hypersensitivity pneumonitis [1].

A multidisciplinary approach including clinical, radiological and pathological evaluation is essential for an accurate diagnosis [26].

\section{Bronchoalveolar lavage}

Bronchoalveolar lavage (BAL) is one of the minimally invasive and safest investigational tools for the differential diagnosis of diffuse parenchymal lung diseases [27, 28]. The characteristic findings of BAL for sarcoidosis include a normal or mildly elevated total cell count with lymphocytosis, a normal percentage of eosinophils and neutrophils, and an absence of plasma cells and foamy alveolar macrophages [29, 30]. Active sarcoidosis tends to show higher lymphocyte counts than inactive sarcoidosis. However, BAL findings may be normal in $10-15 \%$ of patients, despite disease activity. In late or advanced sarcoidosis, neutrophils and mast cells can also be increased [31]. An increased neutrophil count in BAL may be associated with an unfavourable outcome in newly diagnosed patients with sarcoidosis [32, 33]. The importance of the $\mathrm{CD}^{+} / \mathrm{CD}^{+}$ratio for diagnosing sarcoidosis is controversial. $\mathrm{A} \mathrm{CD} 4^{+} / \mathrm{CD} 8^{+}$ratio $>3.5$ indicates the presence of sarcoidosis with a high specificity of $93-96 \%$, although the sensitivity is low, ranging from $53 \%$ to $59 \%[34,35]$. The $\mathrm{CD}^{+} / \mathrm{CD}^{+}$ratio is frequently high in patients with Löfgren's syndrome and acute sarcoidosis, whereas the ratio is usually within the normal range in inactive sarcoidosis.

OzDEMIR et al. [36] demonstrated that the BAL fluid (BALF) concentration of CD95 (Fas), an apoptotic molecule, was significantly higher in patients with chronic sarcoidosis compared with those with spontaneous remission. Heron et al. [37] evaluated the utility of integrin CD103 expressed on CD4 T-lymphocytes in BALF for the diagnosis in 56 patients with sarcoidosis. They demonstrated that the combined use of the $\mathrm{CD} 103^{+} \mathrm{CD}^{+} / \mathrm{CD} 4^{+}$ratio $(<0.2)$ with either the $\mathrm{BAL} \mathrm{CD} 4^{+} / \mathrm{CD} 8^{+}$ratio $(>3)$ or the relative $\mathrm{BAL} /$ peripheral blood $\mathrm{CD} 4^{+} / \mathrm{CD} 8^{+}$ratio $(>2)$ could discriminate sarcoidosis from other interstitial lung diseases with a sensitivity of $66 \%$ and a specificity of $89 \%$.

\section{Endobronchial ultrasound-guided transbronchial needle aspiration}

TBLB is the traditional diagnostic procedure for the demonstration of granuloma in pulmonary sarcoidosis, with a diagnostic accuracy ranging from $40 \%$ to $90 \%$ [38-40]. Endoscopic ultrasonography-guided fine-needle aspiration (EUS-FNA) and EBUS-TBNA are safe and minimally invasive techniques for obtaining granulomatous specimens [41]. Homogeneous low echotexture (88\%) 
and the presence of a germinal central structure (71\%) are the specific ultrasonographic findings in lymph nodes of sarcoidosis [42]. Pathological characteristics for sarcoidosis include the lack of necrotic debris or exudate [43]. In a recent meta-analysis including 14 studies, the diagnostic power of EBUS-TBNA for the diagnosis of sarcoidosis was evaluated in consecutive patient populations with intrathoracic lymphadenopathy, regardless of the suspected underlying aetiology [44]. The pooled diagnostic accuracy, sensitivity and specificity were $79 \%, 84 \%$ and $100 \%$, respectively, indicating a very good test performance even in these unselected patient cohorts with a low overall prevalence of sarcoidosis of only $15 \%$. However, little is known about the diagnostic accuracy of EBUS-TBNA in patients with normal-sized lymph nodes.

Rapid on-site evaluation (ROSE) of biopsy specimens obtained by EBUS-TBNA could provide information on the number of lymph nodes and passes that need to be undertaken. PLIT et al. [45] demonstrated that EBUS-TBNA with ROSE showed a sensitivity, specificity and positive predictive value of $88 \%, 91 \%$ and $98 \%$, respectively, for the diagnosis of sarcoidosis. Interobserver agreement between cytotechnologists and pathologists was good $(\kappa=0.91)$. A recent study showed that ROSE is more important for conventional TBNA than for EBUS-TBNA; when conventional TBNA was combined with ROSE, the diagnostic yield increased significantly and reached a similar sensitivity as for EBUS-TBNA, whereas ROSE did not add to the sensitivity of EBUS-TBNA alone (TBNA with ROSE 72\%, EBUS-TBNA with ROSE 67\%, EBUS-TBNA alone $68 \%$ and TBNA alone $32 \%$; $=0.04$ ) [46].

Potential complications of pneumothorax and bleeding must be considered [47, 48]. A systematic review including 190 studies with 16181 patients with suspected sarcoidosis demonstrated that the incidence of serious adverse events was $0.14 \%$ and no mortality was observed. Serious adverse events were more frequent with EUS-FNA than with EBUS-TBNA (0.30\% versus $0.05 \%)$ [49].

\section{Transbronchial cryobiopsy}

Transbronchial cryobiopsy is a novel technique providing larger lung parenchymal specimens than conventional TBLB [50]. The biopsies are obtained under fluoroscopic guidance using a flexible bronchoscope inserted through a rigid tube into the selected bronchus. Particular attention is given to the position of the biopsy: the cryoprobe is placed perpendicular to the chest wall to assure accurate evaluation of the distance from the thoracic wall by fluoroscopy. A distance of $\sim 10 \mathrm{~mm}$ from the thoracic wall is considered optimal. The probes are cooled with carbon dioxide, which allows the temperature in the probe's tip to decrease to $-75^{\circ} \mathrm{C}$ within several seconds [50].

Tomassetтi et al. [51] demonstrated an increase in diagnostic confidence with the addition of transbronchial cryobiopsy in multidisciplinary interstitial lung disease (ILD) diagnosis. They showed that transbronchial cryobiopsy provided comparable results to surgical lung biopsy in the diagnosis of various ILDs. However, their study did not assess the utility of transbronchial cryobiopsy for the diagnosis of sarcoidosis, because only two patients with the final diagnosis of sarcoidosis were included and both were in the surgical lung biopsy group. Ussavarungsi et al. [52] demonstrated that clinical, radiological and histopathological findings from transbronchial cryobiopsy yielded a definite multidisciplinary diagnosis in $51 \%$ of patients with ILDs ( 38 out of 74 patients), including two patients with sarcoidosis. GrifF et al. [53] demonstrated that the diagnostic yield of transbronchial cryobiopsy was $83 \%$ in sarcoidosis (10 out of 12 patients). BABIAK et al. [54] achieved a diagnostic yield of 95\% in 41 ILD patients including six with sarcoidosis with this technique. Based on these results, transbronchial cryobiopsy has potential as a novel diagnostic tool for sarcoidosis.

Positron emission tomography

${ }^{18}$ F-fluorodeoxyglucose (FDG)-positron emission tomography (PET) is widely used in the evaluation of tumours, vasculitis and inflammatory diseases [55], and is more sensitive than gallium scanning [56, 57]. FDG-PET is likely to be useful for evaluating the extent of inflammatory activity in sarcoidosis in a subset of patients with complicated disease course [58]. MOSTARD et al. [59] showed that positive PET uptake in the lung was associated with HRCT severity and impaired pulmonary function. VorselaARs et al. [60] demonstrated that high maximum standardised uptake value of pulmonary parenchyma in FDG-PET at baseline was associated with improvement in forced vital capacity, suggesting that evaluation by FDG-PET at baseline is useful for therapeutic decision making in sarcoidosis. However, differentiation between granulomatous inflammation and malignancy using FDG-PET/CT is still challenging because of the high false-positive rate $[61,62]$.

L-3- ${ }^{18} \mathrm{~F}$-fluoro- $\alpha$-methyltyrosine (FMT), an amino acid analogue, is accumulated in tumour cells solely via an amino acid transport system, suggesting its higher specificity for evaluating malignancy compared with FDG. KAIRA et al. [63] demonstrated that the use of FMT-PET in combination with FDG-PET may be useful to distinguish sarcoidosis from malignancy. In lung cancer, an increased uptake on FDG-PET was seen in $94 \%$ of patients and on FMT-PET in $88 \%$ of patients, whereas sarcoidosis lesions were positive 
only on FDG-PET and always negative on FMT-PET. ${ }^{18}$ F-fluorothymidine (FLT) is a novel surrogate marker for in vivo assessment of DNA synthesis. FLT has been used for imaging proliferation in several malignant diseases [64]. The utility of FLT-PET for sarcoidosis is still controversial $[65,66]$.

\section{Genetics}

Genetic factors are likely to be associated with disease phenotype and outcome in sarcoidosis. GRUNEWALD and EKLUND [67] demonstrated in 150 patients with an acute onset of sarcoidosis that $99 \%$ of human leukocyte antigen (HLA)-DRB1 ${ }^{\star} 0301 / \mathrm{DQB1}{ }^{\star} 0201$-positive patients showed a spontaneous remission, whereas only $55 \%$ of HLA-DRB1 ${ }^{\star} 0301 / \mathrm{DQB1}{ }^{\star} 0201$-negative patients had a spontaneous remission. These alleles seem to be excellent factors to predict prognosis in Löfgren's syndrome. Löfgren's syndrome and non-Löfgren's syndrome have different genetic susceptibilities and genomic distributions. A shared overlap between these two phenotypes was limited to only 17 single nucleotide polymorphisms, including BTNL2 (butyrophilin-like 2) and HLA-DRA [68].

The BTNL2 gene polymorphism [69-71], HLA-DRB1*14 and HLA-DRB1*12 [72] are independent risk factors for sarcoidosis. A systematic review and meta-analysis demonstrated that BTNL2 G16071A gene polymorphism was associated with susceptibility to granulomatous disease (A versus G: OR 1.25; $\mathrm{p}=0.005$ ) and particularly to sarcoidosis (A versus $\mathrm{G}$ : OR 1.52; $\mathrm{p}<0.001$ ) [73]. The angiotensin-converting enzyme D/D genotype was associated with an increased risk of sarcoidosis (OR 1.21, 95\% CI 1.06-1.38; $I^{2}=48 \%$ ) [74]. However, there is still no routine application of genetic testing in the clinic for the diagnosis or differential diagnosis of sarcoidosis.

\section{Necrotising sarcoid granulomatosis}

Necrotising sarcoid granulomatosis (NSG) is a rare granulomatous disease of the lung with associated vasculitis. It is still controversial whether it is a discrete entity or a variant of nodular sarcoidosis. The main features of NSG include 1) histologically sarcoid-like granuloma with vasculitis and necrosis, 2) radiologically multiple lung nodules without hilar lymphadenopathy, and 3) a benign clinical course. The clinical symptoms of NSG are often nonspecific (e.g. fever, chest pain, weight loss, cough and dyspnoea) and the radiological findings vary widely (e.g. bilateral nodules and masses, cavitation, and pleural effusion). NSG does not usually affect extrapulmonary organs [75].

Typical pathological findings include large areas of parenchymal necrosis surrounded by sarcoid-like granulomatous inflammation and granulomatous vasculitis out of proportion to the granulomatous inflammation [76]. Necrosis in NSG is usually coagulative or caseous. Vasculitis is almost always granulomatous, and involves both veins and arteries [75]. The diagnosis of NSG requires careful exclusion of other similar diseases. Nodular sarcoidosis does not show such extensive vasculitis and diffuse parenchymal necrosis [3]. Granulomatosis with polyangiitis (GPA) is not associated with sarcoid-like nonnecrotising granulomas [3]. Granulomatous infections can be excluded by negative tests for causative microorganisms. As false-negative microbiological results cannot be completely avoided despite the use of the latest technologies, and granulomatous infections can also demonstrate vasculitis, necrosis and sarcoid-like reaction, the exclusion of possible infections is especially important.

\section{Bronchocentric granulomatosis}

Bronchocentric granulomatosis is confined to the lungs and characterised by a destructive, granulomatous inflammation of the bronchioles that might be associated with a nonspecific pathological response to various forms of lung injury [77]. The incidence and prevalence of bronchocentric granulomatosis are still unknown. Approximately half of all cases are associated with asthma or allergic bronchopulmonary aspergillosis.

In such cases, typical findings include blood eosinophilia, elevated total serum IgE and IgE antibodies to Aspergillus species [78]. Gram stain and culture of sputum sometimes show the presence of Aspergillus or Candida species. As bronchocentric granulomatosis is part of a complex tissue response to fungal colonisation in the airways, other associated tissue manifestations of hypersensitivity including mucoid impaction of bronchi, eosinophilic bronchiolitis and eosinophilic pneumonia can also be observed.

Although radiographic findings of bronchocentric granulomatosis vary, single or multiple pulmonary nodules and upper-lobe-predominant unilateral consolidation are relatively common [79]. Mass-like lesions, alveolar infiltrates and reticulonodular infiltrates can also be found, whereas hilar adenopathy and cavitation are infrequent [80]. One case report of FDG-PET demonstrated intermediate activity without significant FDG uptake in bronchocentric granuloma [81].

Bronchocentric granulomatosis is pathologically characterised by peribronchiolar necrotising granulomatous inflammation [77]. Bronchioles are predominantly affected, compared with the larger 
airways. Granulomatous replacement of mucosa and submucosa by palisading, epithelioid and multinucleated histiocytes is the characteristic finding of bronchocentric granulomatosis, which results in the destruction of airway walls [78]. Affected airways may contain necrotic debris. A prominent accompanying eosinophilic infiltrate is important in making the diagnosis. Mucoid impaction of the bronchi is common in the more proximal larger bronchi. Nonspecific extension of the inflammatory infiltrate to neighbouring arteries is frequent but a necrotising vasculitis is not present, in contrast to GPA and eosinophilic GPA (EGPA).

A careful search for an underlying cause, including allergic bronchopulmonary aspergillosis, mycobacterial and fungal infection, rheumatoid arthritis, GPA, and bronchogenic carcinoma, is necessary for the accurate diagnosis of bronchocentric granulomatosis.

\section{Inflammatory bowel disease}

Inflammatory bowel diseases (IBDs) are characterised by nonnecrotising granulomas of the gastrointestinal tract. Although extraintestinal manifestations occur in $21-36 \%$ of patients [82], pulmonary granulomatous manifestations are extremely rare, occurring in $<1 \%$ of patients [83]. Chronic bronchiolitis with nonnecrotising granulomas without the lymphangitic pattern has been reported [84]. BAL may show a lymphocytosis [27]. However, pathological and/or microscopic findings alone cannot discriminate pulmonary involvement of IBD from other granulomatous lung diseases.

\section{Hypersensitivity pneumonitis \\ General diagnostic procedure}

Hypersensitivity pneumonitis, synonymous with extrinsic allergic alveolitis, is a complex syndrome resulting from repeated exposure to a variety of antigenic particles found in the environment [85]. The clinical manifestations have regional characteristics, e.g. summer-type hypersensitivity pneumonitis is limited to Japan. The causative particles for hypersensitivity pneumonitis show a wide variety with a size of $<5 \mu \mathrm{m}$, which include fungal (e.g. Aspergillus and Penicillium species), bacterial, protozoal, animal (mostly bird) and insect proteins, and low-molecular-weight chemical compounds (e.g. isocyanates, zinc, inks and dyes) [86]. Hypersensitivity pneumonitis presents as an acute, subacute or chronic clinical form and overlap is possible. The clinical presentation of hypersensitivity pneumonitis is influenced by several factors including the nature and the amount of inhaled antigen, the intensity and frequency of exposure, and the host immune response, which is likely determined by a genetic background [85].

Although various diagnostic criteria have been proposed for hypersensitivity pneumonitis [87, 88], none of these has been validated. LACASSE et al. [89] suggested a clinical prediction model for a diagnosis of hypersensitivity pneumonitis (table 2). If all of the six predictors in this model are fulfilled, the probability of having hypersensitivity pneumonitis is $98 \%$. If none of the six predictors are present, the probability is $0 \%$. The histological triad of hypersensitivity pneumonitis includes peribronchiolar chronic inflammation, poorly formed small interstitial nonnecrotising granulomas and foci of organising pneumonia. Multinucleated giant cells are randomly scattered within the interstitial inflammation and/or bronchiolar walls.

One of the pitfalls in the diagnosis of hypersensitivity pneumonitis is the effect of cigarette smoking. Hypersensitivity pneumonitis is less frequent in smokers than in nonsmokers under the same exposure [90]. Cigarette smoking seems to be protective against the development of hypersensitivity pneumonitis. Although the mechanisms of the protective effect of smoking for developing hypersensitivity pneumonitis are poorly understood, certain immunological functions such as macrophage activation or lymphocyte proliferation are impaired in the lungs of cigarette smokers [88].

\section{TABLE 2 Predictors of hypersensitivity pneumonitis}

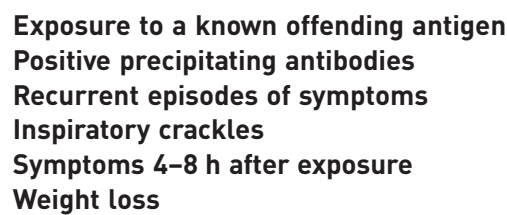

Reproduced and modified from [89] with permission from the publisher. 

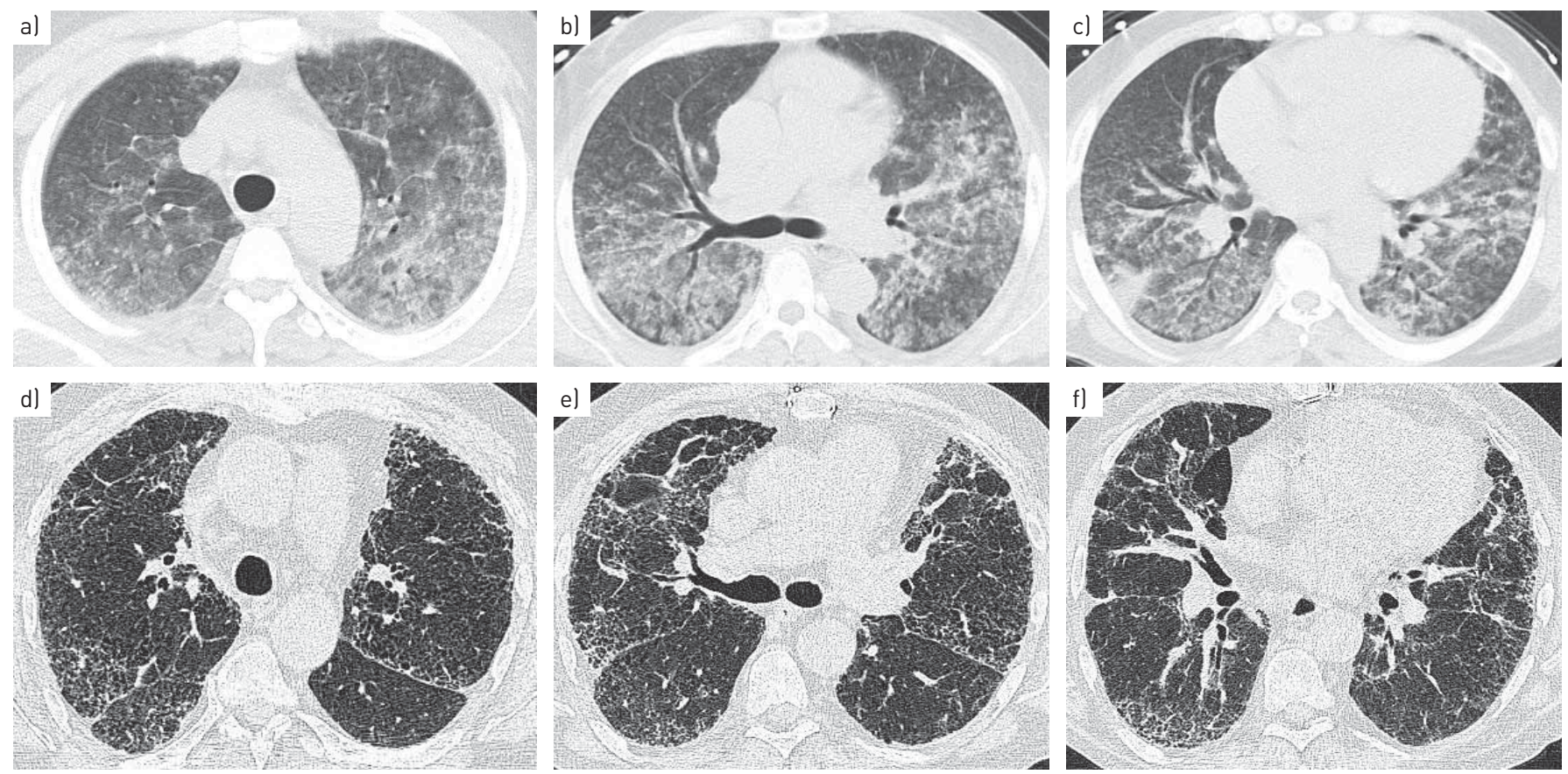

FIGURE 1 Chest high-resolution computed tomography (HRCT) of a-c) acute hypersensitivity pneumonitis and d-f) chronic hypersensitivity pneumonitis. Chest HRCT of acute hypersensitivity pneumonitis shows bilateral ground-glass densities with centrilobular micronodular accentuation and minor consolidation. Chest HRCT of chronic hypersensitivity pneumonitis shows bilateral reticular shadowing, traction bronchiectasis and minor mosaic perfusion along with some micronodules.

High-resolution computed tomography

Chest radiography and HRCT are usually the first steps when evaluating a patient with suspected hypersensitivity pneumonitis. HRCT findings in acute hypersensitivity pneumonitis may be normal [91]. In patients with more severe manifestations of acute hypersensitivity pneumonitis, HRCT shows patchy or diffuse ground-glass attenuation and/or centrilobular poorly defined small nodules. Consolidation is rarely seen (figure 1a-c) [92-97]. Mosaic perfusion is also observed, which represents indirect signs of small airway obstruction (air-trapping) due to a concomitant bronchiolitis. Small nodules are not specific for acute hypersensitivity pneumonitis and are also observed in chronic hypersensitivity pneumonitis.

In subacute hypersensitivity pneumonitis, patchy air-trapping areas on expiratory scans become more prominent, often in a lobular distribution $[93,98]$. Poorly defined small nodules are more prominent in subacute hypersensitivity pneumonitis compared with acute hypersensitivity pneumonitis, which are usually $<5 \mathrm{~mm}$ in diameter and generally have a centrilobular distribution. Although the nodules may sometimes be seen throughout the lungs, they typically distribute in the upper and middle lobes. As a result of the considerable overlap of subacute and chronic hypersensitivity pneumonitis, the findings of chronic hypersensitivity pneumonitis may be observed in subacute hypersensitivity pneumonitis to varying degrees.

In chronic hypersensitivity pneumonitis, the prominent findings on HRCT are the signs of lung fibrosis combined with ground-glass attenuation and centrilobular small nodules. The signs of lung fibrosis include interlobular septal thickening, lobar volume loss, linear/reticular opacities, traction bronchiectasis and honeycombing (figure 1d-f) [92, 99-101]. Traction bronchiectasis is a significant prognostic factor for chronic hypersensitivity pneumonitis. Idiopathic pulmonary fibrosis (IPF) can be differentiated from chronic hypersensitivity pneumonitis by the basal predominance of honeycombing, the absence of relative subpleural sparing and the absence of centrilobular nodules [99]. It is noteworthy that honeycombing was observed in $64 \%$ of patients with chronic hypersensitivity pneumonitis, which was similar to the frequency seen in IPF [99]. Mosaic perfusion can also be useful to differentiate IPF from chronic hypersensitivity pneumonitis (absent in IPF, present in hypersensitivity pneumonitis). Nonspecific interstitial pneumonia (NSIP) can be differentiated from chronic hypersensitivity pneumonitis by the subpleural sparing, absence of lobular areas with ground-glass attenuation and lack of honeycombing [102]. Sarcoidosis can be differentiated from chronic hypersensitivity pneumonitis by the different distribution of the micronodules (perilymphatic/subpleural/along fissures in sarcoidosis versus centrilobular in hypersensitivity pneumonitis) and by the lack of mosaic perfusion in sarcoidosis [1]. 


\section{Bronchoalveolar lavage}

BAL is a highly sensitive method to detect hypersensitivity pneumonitis. An increase in the total cell count (usually $>20 \times 10^{6}$ in a total of $100 \mathrm{~mL}$ BALF) with a remarkable increment of lymphocytes (usually $>50 \%$ ) is characteristic for hypersensitivity pneumonitis [103]. BAL lymphocytes show the highest count in hypersensitivity pneumonitis of all ILDs. This increase is unusual in fibrotic ILDs such as IPF [104, 105] and a BAL lymphocytosis with a cut-off level of 30\% favourably differentiates chronic hypersensitivity pneumonitis from IPF [104]. An increase of $\mathrm{CD}^{+}$T-cells in BALF of hypersensitivity pneumonitis patients results in a low $\mathrm{CD} 4^{+} / \mathrm{CD}^{+}$ratio with mean values of $0.5-1.5$. However, the ratio is variable and may be frequently increased in chronic hypersensitivity pneumonitis. Small numbers of neutrophils, eosinophils, mast cells and, more characteristically, plasma cells are also found in BALF [95, 106-109].

Activated T-cells in hypersensitivity pneumonitis show folded nuclei and/or broad cytoplasm, and have increased expression of counter-ligand CD28 [110]. Macrophages are also activated in hypersensitivity pneumonitis, showing foamy macrophages and an increased expression of CD80/CD86 [111]. Lymphocyte subsets of HLA-DR ${ }^{+} \mathrm{CD}^{+}$T-cells and natural killer T-cells in BALF may differentiate hypersensitivity pneumonitis from sarcoidosis. Natural killer T-cells were over seven-fold higher and HLA-DR ${ }^{+} \mathrm{CD}^{+}$ T-cells were two-fold higher in hypersensitivity pneumonitis compared with sarcoidosis [112].

Cytokines in BALF are also different in hypersensitivity pneumonitis. CCL18 is a member of the CC chemokine family and is chemotactic for T-lymphocytes. The concentration of CCL18 both in serum and BALF was significantly increased in hypersensitivity pneumonitis compared with IPF, respiratory bronchiolitis ILD/desquamative interstitial pneumonia and cryptogenic organising pneumonia [113]. The interleukin-6 polymorphism on the CXC chemokine motif ligand CXCL5 (ENA78) in BALF was specific for hypersensitivity pneumonitis compared with sarcoidosis and IPF [114].

\section{Transbronchial cryobiopsy}

TOMASSETTi et al. [51] demonstrated that $17 \%$ of patients, mostly idiopathic NSIP and hypersensitivity pneumonitis, were reclassified as IPF after having obtained histopathological information from transbronchial cryobiopsy specimens. UsSAVARUNGSI et al. [52] investigated the diagnostic utility of transbronchial cryobiopsy in 74 patients with diffuse parenchymal lung disease. They observed that the most frequent histopathological pattern was granulomatous inflammation $(n=12,16 \%)$, resulting in the final diagnoses of hypersensitivity pneumonitis in six patients $(8 \%)$. The rates of pneumothorax and bleeding were $1.4 \%$ and $22 \%$, respectively. GRIFF et al. [53] demonstrated among a total of 52 patients with ILDs that transbronchial cryobiopsy was diagnostic in six out of seven patients (86\%) with hypersensitivity pneumonitis. Despite the encouraging results of transbronchial cryobiopsy, the use of this technique is not yet recommended as a standard procedure for the diagnosis of suspected hypersensitivity pneumonitis, because chronic hypersensitivity pneumonitis and IPF may be histologically similar, especially in advanced stages. In general, histological changes in chronic hypersensitivity pneumonitis may not be different from the patterns found in other fibrotic lung diseases. Isolated usual interstitial pneumonia-like or fibrotic NSIP-like patterns have been reported in chronic hypersensitivity pneumonitis. Nevertheless, the greater specimen size obtained by the use of transbronchial cryobiopsy could allow for a more confident evaluation of granulomas and/or other characteristic histopathological features.

\section{Genetics}

Hypersensitivity pneumonitis develops in only a small proportion of individuals exposed to pathogenetic antigens, suggesting that additional host/environmental factors may play a role. FALFÁN-VALENCIAE et al. [115] investigated the genetic susceptibility to hypersensitivity pneumonitis, and found that the frequency of HLA-DRB1 ${ }^{\star}$ 04:07-DQB1 ${ }^{\star 03: 02, ~} \mathrm{DRB} 1^{\star}$ 04:05-DQB1 ${ }^{\star} 03: 02$ and $\mathrm{DRB1}^{\star}{ }^{\star 04: 03-D Q B 1}{ }^{\star} 03: 02$ haplotypes was higher in patients with hypersensitivity pneumonitis compared with healthy controls. In addition, the combination of HLA-DRB $1^{\star} 04$ alleles and the tumour necrosis factor-238 GG genotype was significantly increased in the hypersensitivity pneumonitis group compared with healthy controls (OR 6.93; $\mathrm{p}=0.01$ ). The low-molecular-weight proteasome (synonymous with proteasome subunit $\beta(P S M B)$ ) genes code for subunits of the enzyme that degrades proteins into peptides for the major histocompatibility complex class I pathway. CAMARENA et al. [116] demonstrated a significant increase of the PSMB8 KQ genotype frequency in patients with hypersensitivity pneumonitis compared with healthy controls (OR 7.25, 95\% CI 2.61-21.3; $\mathrm{p}=0.000034$ ). Although these findings suggest that various genotypes may increase the risk of developing hypersensitivity pneumonitis, there is currently no clinical value of genetic testing in the diagnosis or differential diagnosis of hypersensitivity pneumonitis.

\section{Drug-induced granulomatous lung disease}

Drug-induced ILD can present as a granulomatous lung disease, with or without hilar and/or mediastinal lymphadenopathy. Updated information of drug toxicity can be found at www.pneumotox.com. 
Granulomas of drug-induced ILD are typically nonnecrotising. Depending on the immune status of patients, special stains and molecular analyses are necessary to differentiate drug-induced ILD from mycobacteria, Pneumocystis or other infections. A number of drugs (methotrexate, interferon, Bacillus Calmette-Guérin, infliximab, etanercept, leflunomide, mesalamine and sirolimus) can be causative of granulomas in drug-induced respiratory diseases. Pathological evaluation alone does not allow the diagnosis of drug-induced granulomatous lung disease, because information about the exposure to the causative drugs is essential for the accurate diagnosis.

\section{Hot tub lung}

Hot tub lung is a syndrome that combines features of hypersensitivity pneumonitis and M. avium complex infection resulting from exposure to contaminated hot tubs, spas and Jacuzzis. Chest HRCT shows ground-glass attenuation and scattered small nodules. Pathological findings are similar to those of typical hypersensitivity pneumonitis. However, the interstitial pneumonia tends to be less prominent and the usually nonnecrotising granulomas are well formed, which are frequently distributed within the airway lumen rather than in the peribronchiolar interstitium [117]. Cultures and a history of exposure are necessary for diagnosis.

\section{Berylliosis}

Berylliosis is characterised by a granulomatous reaction in the lung to inhaled beryllium. The clinical, radiological and histopathological findings mimic sarcoidosis, with lymphangitic distribution and hilar lymph node involvement [1]. In addition to granulomas, histopathology shows interstitial inflammation which rather resembles hypersensitivity pneumonitis. A history of exposure to beryllium and a positive beryllium lymphocyte transformation test are crucial for the accurate diagnosis of berylliosis.

\section{Talc-induced granulomatosis}

Drug abusers, especially of cocaine and crack, can develop a broad spectrum of acute and chronic lung diseases. The method of administration (oral, nasal or intravenous), dose size, frequency of exposure and presence of associated substances are associated with the different lung manifestations. Talc (hydrated magnesium silicate) is the most frequently used carrier substance for oral medications. If such medications are applied intravenously by drug abusers, typical pathological findings are perivascular location of foreign body-containing granulomas. Talc can be found in the granulomas as a sheet-like substance [118].

\section{Granulomatosis with polyangiitis}

GPA, previously known as Wegener's granulomatosis, and microscopic polyangiitis (MPA) are defined as systemic vasculitis usually without eosinophilia that predominantly affects small vessels, and are now categorised along with EGPA in the group termed antineutrophil cytoplasmic antibody (ANCA)-associated vasculitis (AAV) [119]. The positive rate of proteinase 3 (PRTN3)-ANCA is $>90 \%$ in extended GPA and 75\% in limited GPA without renal involvement [120]. Typical histological findings for GPA are necrotising granulomas accompanied by necrotising vasculitis, resembling abscesses at low magnification.

CABRAL et al. [121] investigated the clinical characteristics of paediatric patients with AAV in an ARChiVe (A Registry for Childhood Vasculitis: e-entry) cohort study. Older age at disease onset (14 versus 11 years), more frequent pulmonary manifestations ( $74 \%$ versus $44 \%$ ), less frequent gastrointestinal manifestations (36\% versus $58 \%$ ) and less frequent renal failure requiring dialysis (13\% versus 25\%) formed the characteristic clinical profile for patients with GPA compared with those with MPA. Although the diagnostic utility of FDG-PET/CT for GPA is limited, FDG-PET/CT may be useful for the detection of occult sites of disease activity and the extent of disease activity [122].

Merkel et al. [123] identified risk alleles relevant to AAV in a genome-wide association and subsequent replication study including 1986 patients with AAV. They detected HLA-DPB1 and HLA-DPA1 variants were associated with GPA, and HLA-DQA2 and HLA-DQB1 variants were associated with MPA. PRTN3 and SERPINA1 (serpin family A member 1) loci were also associated with GPA.

\section{Eosinophilic granulomatosis with polyangiitis}

EGPA, previously known as Churg-Strauss syndrome, is defined as a necrotising granulomatous inflammation with marked eosinophil infiltration in the respiratory tract, with necrotising vasculitis predominantly affecting small-to-medium size vessels, and associated with asthma and eosinophilia [119]. Asthma and eosinophilia $>1.5 \times 10^{9} \mathrm{~L}^{-1}$ or $10 \%$ of leukocytes can be found in all patients with EGPA [124]. Pathological examination contributes to the diagnosis of EGPA in 57\% of patients, demonstrating necrotising vasculitis of small-to-medium size vessels (18\%), leukocytoclastic capillaritis (13\%), eosinophilic infiltration of the arterial wall $(8 \%)$ or of the adjacent tissue (18\%), extravascular granulomas 
(6\%) and/or giant cells (4\%). Predominant HRCT features include ground-glass opacities (39\%), bronchial wall thickening (32\%), consolidation $(28 \%)$ and micronodules $(<3 \mathrm{~mm})(24 \%)$. BAL cell differentials show a mean eosinophilia of $33 \%$. ANCAs are positive at the time of diagnosis in $31 \%$ of patients [124].

The Fcy receptor 3B (FCGR3B) is mainly expressed on neutrophils and contributes to the clearance of immune complexes by neutrophils. MARTORANA et al. [125] demonstrated that FCGR3B deficiency predisposes to EGPA and is particularly associated with vasculitis on biopsy (OR 3.23, 95\% CI 1.3-8.02; $\mathrm{p}=0.008)$.

\section{Rheumatoid nodules}

Rheumatoid nodules are necrotising granulomas observed in $20 \%$ of patients with rheumatoid arthritis. They are usually located subcutaneously but may also occur in the lungs as subpleural necrobiotic nodules, either multiple or solitary, with an incidence of $<1 \%$ [126]. The size of these nodules varies from 1 to $10 \mathrm{~mm}$. Typical pathological findings include abundant central necrosis with a rim of palisading histiocytes surrounded by infiltrates of lymphocytes and plasma cells. Although vasculitis can be found, necrotising vasculitis is absent [127].

\section{Pulmonary Langerhans cell histiocytosis}

Pulmonary Langerhans cell histiocytosis (PLCH), synonymous with eosinophilic granuloma, is a rare lung disease of unknown cause, primarily affecting young adults [128-130]. As nearly all patients with adult PLCH have a history of current of recent cigarette smoking, smoking appears to be one of the important aetiological factors. The clinical presentation of $\mathrm{PLCH}$ is usually nonspecific, and symptoms include nonproductive cough, dyspnoea, fatigue, chest pain, weight loss and fever. However, some patients with PLCH experience life-threatening multiorgan failure. Chest HRCT typically shows multiple cysts and nodules with a middle- to upper-lobe predominance. These cysts may be isolated or confluent, sometimes mimicking centrilobular emphysema [128]. The nodules are usually ill defined or stellate form with a size of $2-10 \mathrm{~mm}[131,132]$.

PLCH is pathologically characterised by an accumulation of activated Langerhans cells in granulomas accompanied by eosinophils and lymphocytes. PLCH granulomas are associated with formation of cystic appearing structures $>1 \mathrm{~cm}$ in size. BALF analysis usually shows the presence of $\mathrm{CD}_{1} \mathrm{a}^{+}$and/or CD207 (Langerin) $^{+}$cells (Langerhans cells) accounting for $>5 \%$ of total cells [105]. However, the cut-off value of $5 \%$ has not been established conclusively and $<5 \%$ of Langerhans cells does not exclude the diagnosis of PLCH. A low proportion of Langerhans cells can be seen in other clinical settings, including current smokers, other ILDs and bronchioloalveolar carcinoma. The diagnostic yield of TBLB is limited, ranging from only $10 \%$ to $40 \%$, because of the focal distribution of the lesions [133].

FDG-PET scan shows increased uptake in the granulomas of PLCH. Positive FDG uptake is more likely to be associated with a nodular radiographic pattern, whereas negative FDG uptake is more likely to be associated with a cystic pattern with fewer nodules [134]. OBERT et al. [135] recently demonstrated that FDG-PET might have some utility for evaluating extrapulmonary lesions of PLCH (e.g. bone and thyroid). However, the sensitivity of FDG-PET for pulmonary involvement was low (three out of 12 patients (25\%)). Accordingly, the role of FDG-PET in the diagnosis of PLCH is currently limited.

\section{Granulomatous-lymphocytic interstitial lung disease}

Common variable immunodeficiency (CVID) is a primary immunodeficiency characterised by B-lymphocyte dysfunction and hypogammaglobulinaemia. Patients with CVID frequently demonstrate recurrent respiratory tract infections [136]. Granulomatous and lymphoproliferative inflammation sometimes affects small airways and the pulmonary interstitium, this is termed granulomatouslymphocytic ILD (GLILD). The pathological changes are complex, and include follicular bronchiolitis, lymphoid hyperplasia, lymphocytic interstitial pneumonia and sarcoid-like granulomatous reactions. The incidence of GLILD in CVID ranges from $8 \%$ to $22 \%$ [137]. Impaired T-cell function and subsequent impaired antigen handling has been considered as a possible mechanism of GLILD [138].

Common physical findings of GLILD include dyspnoea, splenomegaly, lymphadenopathy and/or liver disease in the context of multisystem granulomatous/inflammatory involvement. Pulmonary function tests show a restrictive pattern with a low diffusing capacity of the lung for carbon monoxide. Bronchoscopic examination for bacterial and mycobacterial culture is necessary in the diagnostic work-up for GLILD. There is no consensus on other tests, including TBLB, PCR for mycobacteria, other atypical pathogens including viruses, routine tests for Pneumocystis, BAL cell differentials and lymphocyte phenotyping [137].

Typical radiological findings of GLILD on HRCT include solid nodules $(<3 \mathrm{~cm})$, semi-solid nodules, pure ground-glass opacities, patchy consolidations, reticular densities, enlarged hilar and/or mediastinal lymph 
nodes, and splenomegaly [137]. FDG-PET/CT may be beneficial for detecting areas of increased metabolic activity in the lungs and lymph nodes, which can be detected by FDG-PET/CT, even if lymph nodes are not enlarged [139].

Pathological examinations including immunostaining for CD3, CD4, CD8 and CD20 are recommended, and also evaluating clonality to exclude lymphoma, since there is an increased risk for the development of malignant lymphoma in patients with CVID [137]. The presences of granulomatous inflammation, peribronchiolar lymphoid proliferation, interstitial lymphoid proliferation and $\mathrm{CD}^{+}$cell predominance are suggestive of GLILD. Conversely, the presence of eosinophils is not typical for GLILD.

\section{Aspiration pneumonia}

Aspiration of a variety of substances, including oropharyngeal bacteria, foreign bodies and gastric contents, leads to an aspiration pneumonia. Typical pathological findings include acute necrotising bronchopneumonia accompanied by foreign body granulomas or multinucleated giant cells containing aspirated foreign material [140]. Organising pneumonia can also be found. No recent advances have been reported for improving the diagnostic accuracy of aspiration pneumonia.

\section{Conclusions}

The recent advances in the diagnostic procedures for granulomatous lung diseases have been reviewed. Although some of the diagnostic procedures have potential to improve diagnostic accuracy, they cannot yet routinely be used in practice. As granuloma alone is a nonspecific histopathological finding, the multidisciplinary approach is important for a confident diagnosis. Figure 2 summarises the diagnostic algorithm for granulomatous lung diseases. Characterisation of accompanying histological findings and evaluation of clinical and radiological findings are crucial to achieve accurate diagnosis.

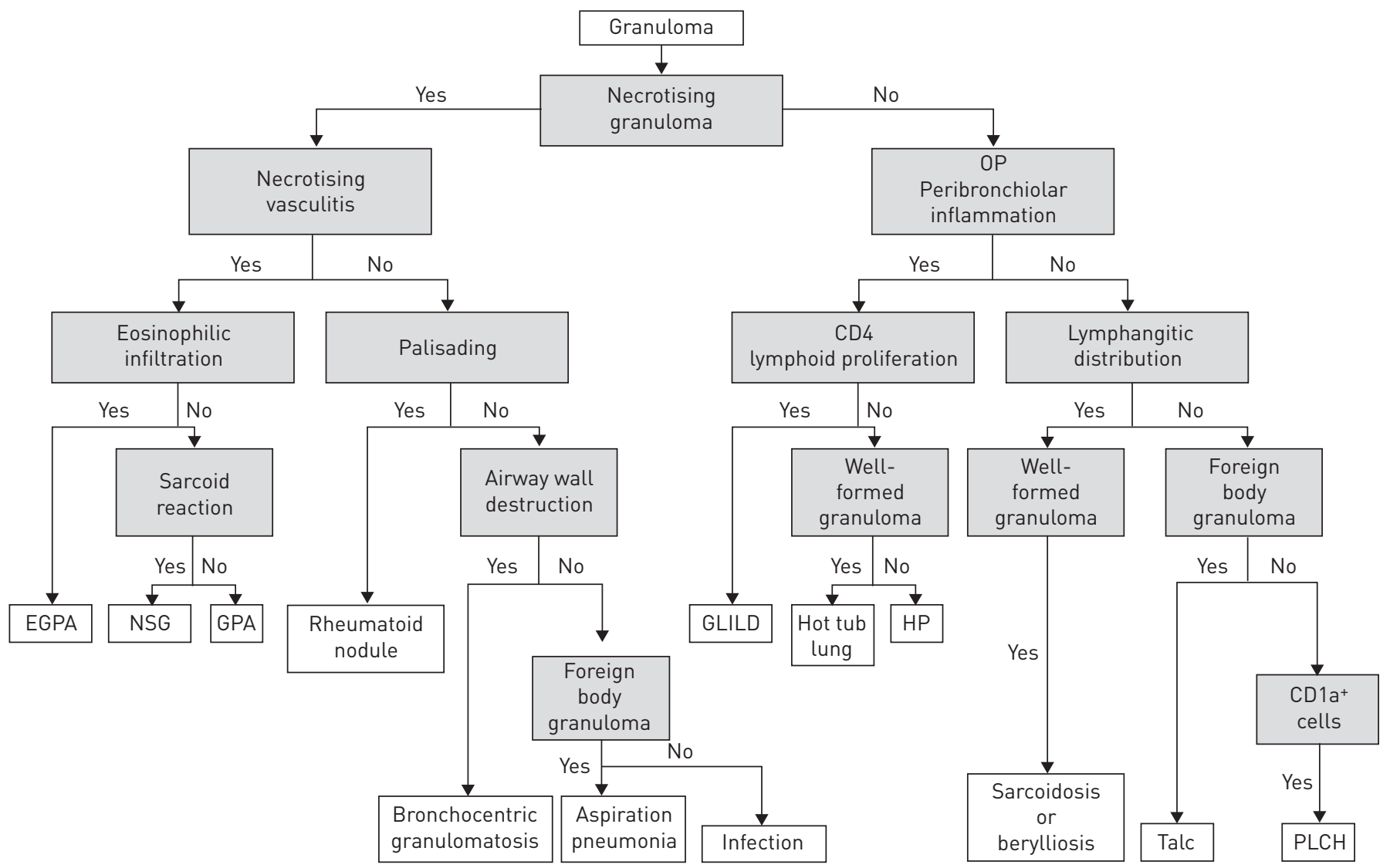

FIGURE 2 Diagnostic algorithm of granulomatous lung diseases. OP: organising pneumonia; EGPA: eosinophilic granulomatosis with polyangiitis; NSG: necrotising sarcoid granulomatosis; GPA: granulomatosis with polyangiitis; GLILD: granulomatous-lymphocytic interstitial lung disease; HP: hypersensitivity pneumonitis; PLCH: pulmonary Langerhans cell histiocytosis. 


\section{References}

1 Mukhopadhyay S, Gal AA. Granulomatous lung disease: an approach to the differential diagnosis. Arch Pathol Lab Med 2010; 134: 667-690.

2 Woodard BH, Rosenberg SI, Farnham R, et al. Incidence and nature of primary granulomatous inflammation in surgically removed material. Am J Surg Pathol 1982; 6: 119-129.

3 Katzenstein A-LA. Katzenstein and Askin's Surgical Pathology of Non-Neoplastic Lung Disease. 4th Edn. Philadelphia, WB Saunders, 2006.

4 Kommareddi S, Abramowsky CR, Swinehart GL, et al. Nontuberculous mycobacterial infections: comparison of the fluorescent auramine-O and Ziehl-Neelsen techniques in tissue diagnosis. Hum Pathol 1984; 15: 1085-1089.

5 Eom JS, Mok JH, Lee MK, et al. Efficacy of TB-PCR using EBUS-TBNA samples in patients with intrathoracic granulomatous lymphadenopathy. BMC Pulm Med 2015; 15: 166.

6 Dhooria S, Agarwal R, Aggarwal AN, et al. Differentiating tuberculosis from sarcoidosis by sonographic characteristics of lymph nodes on endobronchial ultrasonography: a study of 165 patients. J Thorac Cardiovasc Surg 2014; 148: 662-667.

7 Boehme CC, Nabeta P, Hillemann D, et al. Rapid molecular detection of tuberculosis and rifampin resistance. N Engl J Med 2010; 363: 1005-1015.

8 Steingart KR, Schiller I, Horne DJ, et al. Xpert MTB/RIF assay for pulmonary tuberculosis and rifampicin resistance in adults. Cochrane Database Syst Rev 2014; 1: CD009593.

9 Luetkemeyer AF, Firnhaber C, Kendall MA, et al. Evaluation of Xpert MTB/RIF versus AFB smear and culture to identify pulmonary tuberculosis in patients with suspected tuberculosis from low and higher prevalence settings. Clin Infect Dis 2016; 62: 1081-1088.

10 Sanchez-Padilla E, Merker M, Beckert P, et al. Detection of drug-resistant tuberculosis by Xpert MTB/RIF in Swaziland. N Engl J Med 2015; 372: 1181-1182.

11 Dhooria S, Gupta N, Bal A, et al. Role of Xpert MTB/RIF in differentiating tuberculosis from sarcoidosis in patients with mediastinal lymphadenopathy undergoing EBUS-TBNA: a study of 147 patients. Sarcoidosis Vasc Diffuse Lung Dis 2016; 33: 258-266.

12 Porvaznik I, Solovic I, Mokry J. Non-tuberculous mycobacteria: classification, diagnostics, and therapy. Adv Exp Med Biol 2017; 944: 19-25.

13 Griffith DE, Aksamit T, Brown-Elliott BA, et al. An official ATS/IDSA statement: diagnosis, treatment, and prevention of nontuberculous mycobacterial diseases. Am J Respir Crit Care Med 2007; 175: 367-416.

14 Reich JM, Johnson RE. Mycobacterium avium complex pulmonary disease presenting as an isolated lingular or middle lobe pattern. The Lady Windermere syndrome. Chest 1992; 101: 1605-1609.

15 Wallace JM, Hannah JB. Mycobacterium avium complex infection in patients with the acquired immunodeficiency syndrome. A clinicopathologic study. Chest 1988; 93: 926-932.

16 Corpe RF, Runyon EH, Lester W. Status of disease due to unclassified mycobacteria. A statement of the Subcommittee on Unclassified Mycobacteria of the Committee on Therapy. Am Rev Respir Dis 1963; 87: $459-461$.

17 Valdivia L, Nix D, Wright M, et al. Coccidioidomycosis as a common cause of community-acquired pneumonia. Emerg Infect Dis 2006; 12: 958-962.

18 Deppisch LM, Donowho EM. Pulmonary coccidioidomycosis. Am J Clin Pathol 1972; 58: 489-500.

19 Huang CJ, Yang MC, Ueng SH. Large cryptococcoma mimicking lung cancer in an HIV-negative, type 2 diabetic patient. J Thorac Imag 2005; 20: 115-117.

20 Goodwin RA Jr, Shapiro JL, Thurman GH, et al. Disseminated histoplasmosis: clinical and pathologic correlations. Medicine 1980; 59: 1-33.

21 Costabel U, Bonella F, Ohshimo S, et al. Diagnostic modalities in sarcoidosis: BAL, EBUS, and PET. Semin Respir Crit Care Med 2010; 31: 404-408.

22 Ricker W, Clark M. Sarcoidosis; a clinicopathologic review of 300 cases, including 22 autopsies. Am J Clin Pathol 1949; 19: 725-749.

23 Longcope WT, Freiman DG. A study of sarcoidosis - based on a combined investigation of 160 cases including 30 autopsies from the Johns Hopkins Hospital and Massachusetts General Hospital. Medicine 1952; 31: 1-132.

24 Mitchell DN, Scadding JG, Heard BE, et al. Sarcoidosis - histopathological definition and clinical diagnosis. J Clin Pathol 1977; 30: 395-408.

25 Rosen Y. Pathology of sarcoidosis. Semin Respir Crit Care Med 2007; 28: 36-52.

26 Costabel U, Ohshimo S, Guzman J. Diagnosis of sarcoidosis. Curr Opin Pulm Med 2008; 14: 455-461.

27 Costabel U, Guzman J. Bronchoalveolar lavage in interstitial lung disease. Curr Opin Pulm Med 2001; 7: 255-261.

28 Reynolds HY. Bronchoalveolar lavage - obtaining biologic specimens from the respiratory tract surface. Sarcoidosis Vasc Diffuse Lung Dis 2008; 25: 5-9.

29 Costabel U, Guzman J, Drent M. Diagnostic approach to sarcoidosis. In: Drent M, Costabel U, eds. Sarcoidosis (ERS Monograph). Sheffield, European Respiratory Society, 2005; pp. 259-264.

30 Drent M, Mansour K, Linssen C. Bronchoalveolar lavage in sarcoidosis. Semin Respir Crit Care Med 2007; 28: 486-495.

31 Bjermer L, Rosenhall L, Angstrom T, et al. Predictive value of bronchoalveolar lavage cell analysis in sarcoidosis. Thorax 1988; 43: 284-288.

32 Drent M, Jacobs JA, de Vries J, et al. Does the cellular bronchoalveolar lavage fluid profile reflect the severity of sarcoidosis? Eur Respir J 1999; 13: 1338-1344.

33 Ziegenhagen MW, Rothe ME, Schlaak M, et al. Bronchoalveolar and serological parameters reflecting the severity of sarcoidosis. Eur Respir J 2003; 21: 407-413.

34 Winterbauer RH, Lammert J, Selland M, et al. Bronchoalveolar lavage cell populations in the diagnosis of sarcoidosis. Chest 1993; 104: 352-361.

35 Korosec P, Rijavec M, Silar M, et al. Deficiency of pulmonary Valpha24 Vbeta11 natural killer T cells in corticosteroid-naive sarcoidosis patients. Respir Med 2010; 104: 571-577.

36 Ozdemir OK, Celik G, Dalva K, et al. High CD95 expression of BAL lymphocytes predicts chronic course in patients with sarcoidosis. Respirology 2007; 12: 869-873. 
Heron M, Slieker WA, Zanen P, et al. Evaluation of CD103 as a cellular marker for the diagnosis of pulmonary sarcoidosis. Clin Immunol 2008; 126: 338-344.

American Thoracic Society, European Respiratory Society, World Association of Sarcoidosis and Other Granulomatous Disorders. Statement on sarcoidosis. Joint Statement of the American Thoracic Society (ATS), the European Respiratory Society (ERS) and the World Association of Sarcoidosis and Other Granulomatous Disorders (WASOG) adopted by the ATS Board of Directors and by the ERS Executive Committee, February 1999. Am J Respir Crit Care Med 1999; 160: 736-755.

Gilman MJ, Wang KP. Transbronchial lung biopsy in sarcoidosis. An approach to determine the optimal number of biopsies. Am Rev Respir Dis 1980; 122: 721-724.

Koonitz CH, Joyner LR, Nelson RA. Transbronchial lung biopsy via the fiberoptic bronchoscope in sarcoidosis. Ann Intern Med 1976; 85: 64-66.

Annema JT, Rabe KF. State of the art lecture: EUS and EBUS in pulmonary medicine. Endoscopy 2006; 38: Suppl. 1, S118-S122.

Imai $\mathrm{N}$, Imaizumi $\mathrm{K}$, Ando $\mathrm{M}$, et al. Echoic features of lymph nodes with sarcoidosis determined by endobronchial ultrasound. Intern Med 2013; 52: 1473-1478.

Cancellieri A, Leslie KO, Tinelli C, et al. Sarcoidal granulomas in cytological specimens from intrathoracic adenopathy: morphologic characteristics and radiographic correlations. Respiration 2013; 85: 244-251.

Trisolini R, Lazzari Agli L, Tinelli C, et al. Endobronchial ultrasound-guided transbronchial needle aspiration for diagnosis of sarcoidosis in clinically unselected study populations. Respirology 2015; 20: 226-234.

Plit ML, Havryk AP, Hodgson A, et al. Rapid cytological analysis of endobronchial ultrasound-guided aspirates in sarcoidosis. Eur Respir J 2013; 42: 1302-1308.

Madan K, Dhungana A, Mohan A, et al. Conventional transbronchial needle aspiration versus endobronchia ultrasound-guided transbronchial needle aspiration, with or without rapid on-site evaluation, for the diagnosis of sarcoidosis: a randomized controlled trial. J Bronchology Interv Pulmonol 2017; 24: 48-58.

Oki M, Saka H, Kitagawa C, et al. Real-time endobronchial ultrasound-guided transbronchial needle aspiration is useful for diagnosing sarcoidosis. Respirology 2007; 12: 863-868.

Wong M, Yasufuku K, Nakajima T, et al. Endobronchial ultrasound: new insight for the diagnosis of sarcoidosis. Eur Respir J 2007; 29: 1182-1186.

von Bartheld MB, van Breda A, Annema JT. Complication rate of endosonography (endobronchial and endoscopic ultrasound): a systematic review. Respiration 2014; 87: 343-351.

Casoni GL, Tomassetti S, Cavazza A, et al. Transbronchial lung cryobiopsy in the diagnosis of fibrotic interstitial lung diseases. PLoS One 2014; 9: e86716.

Tomassetti S, Wells AU, Costabel U, et al. Bronchoscopic lung cryobiopsy increases diagnostic confidence in the multidisciplinary diagnosis of idiopathic pulmonary fibrosis. Am J Respir Crit Care Med 2016; 193: 745-752.

Ussavarungsi K, Kern RM, Roden AC, et al. Transbronchial cryobiopsy in diffuse parenchymal lung disease: retrospective analysis of 74 cases. Chest 2017; 151: 400-408.

Griff S, Schonfeld N, Ammenwerth W, et al. Diagnostic yield of transbronchial cryobiopsy in non-neoplastic lung disease: a retrospective case series. BMC Pulm Med 2014; 14: 171.

Babiak A, Hetzel J, Krishna G, et al. Transbronchial cryobiopsy: a new tool for lung biopsies. Respiration 2009; 78: 203-208.

Nguyen BD. F-18 FDG PET imaging of disseminated sarcoidosis. Clin Nucl Med 2007; 32: 53-54.

Nishiyama Y, Yamamoto Y, Fukunaga K, et al. Comparative evaluation of ${ }^{18} \mathrm{~F}$-FDG PET and ${ }^{67} \mathrm{Ga}$ scintigraphy in patients with sarcoidosis. J Nucl Med 2006; 47: 1571-1576.

Futamatsu H, Suzuki J, Adachi S, et al. Utility of gallium-67 scintigraphy for evaluation of cardiac sarcoidosis with ventricular tachycardia. Int J Cardiovasc Imaging 2006; 22: 443-448.

Cremers JP, Van Kroonenburgh MJ, Mostard RL, et al. Extent of disease activity assessed by ${ }^{18} \mathrm{~F}-\mathrm{FDG}$ PET/CT in a Dutch sarcoidosis population. Sarcoidosis Vasc Diffuse Lung Dis 2014; 31: 37-45.

Mostard RL, Verschakelen JA, van Kroonenburgh MJ, et al. Severity of pulmonary involvement and ${ }^{18} \mathrm{~F}-\mathrm{FDG}$ PET activity in sarcoidosis. Respir Med 2013; 107: 439-447.

Vorselaars AD, Crommelin HA, Deneer VH, et al. Effectiveness of infliximab in refractory FDG PET-positive sarcoidosis. Eur Respir J 2015; 46: 175-185.

Teirstein AS, Machac J, Almeida O, et al. Results of 188 whole-body fluorodeoxyglucose positron emission tomography scans in 137 patients with sarcoidosis. Chest 2007; 132: 1949-1953.

Huber H, Hodolic M, Stelzmuller I, et al. Malignant disease as an incidental finding at ${ }^{18} \mathrm{~F}-\mathrm{FDG}-\mathrm{PET} / \mathrm{CT}$ scanning in patients with granulomatous lung disease. Nucl Med Commun 2015; 36: 430-437.

Kaira K, Oriuchi N, Otani Y, et al. Diagnostic usefulness of fluorine-18-alpha-methyltyrosine positron emission tomography in combination with ${ }^{18} \mathrm{~F}$-fluorodeoxyglucose in sarcoidosis patients. Chest 2007; 131: 1019-1027.

Tehrani OS, Shields AF. PET imaging of proliferation with pyrimidines. J Nucl Med 2013; 54: 903-912.

Norikane T, Yamamoto Y, Maeda Y, et al. ${ }^{18}$ F-FLT PET imaging in a patient with sarcoidosis with cardiac involvement. Clin Nucl Med 2015; 40: 433-434.

Rayamajhi SJ, Mittal BR, Maturu VN, et al. ${ }^{18}$ F-FDG and ${ }^{18}$ F-FLT PET/CT imaging in the characterization of mediastinal lymph nodes. Ann Nucl Med 2016; 30: 207-216.

Grunewald J, Eklund A. Sex-specific manifestations of Lofgren's syndrome. Am J Respir Crit Care Med 2007; 175: $40-44$.

Rivera NV, Ronninger M, Shchetynsky K, et al. High-density genetic mapping identifies new susceptibility variants in sarcoidosis phenotypes and shows genomic-driven phenotypic differences. Am J Respir Crit Care Med 2016; 193: 1008-1022.

Iannuzzi MC. Advances in the genetics of sarcoidosis. Proc Am Thorac Soc 2007; 4: 457-460.

Valentonyte R, Hampe J, Huse K, et al. Sarcoidosis is associated with a truncating splice site mutation in BTNL2. Nat Genet 2005; 37: 357-364.

Rybicki BA, Walewski JL, Maliarik MJ, et al. The BTNL2 gene and sarcoidosis susceptibility in African Americans and Whites. Am J Hum Genet 2005; 77: 491-499.

Spagnolo P, Sato H, Grutters JC, et al. Analysis of BTNL2 genetic polymorphisms in British and Dutch patients with sarcoidosis. Tissue Antigens 2007; 70: 219-227. 
Tong X, Ma Y, Niu X, et al. The BTNL2 G16071A gene polymorphism increases granulomatous disease susceptibility: a meta-analysis including FPRP test of 8710 participants. Medicine 2016; 95: e4325.

Yang H, Mo T, Nie W, et al. Angiotensin converting enzyme I/D polymorphism and sarcoidosis risk. Sarcoidosis Vasc Diffuse Lung Dis 2016; 32: 284-288.

Rosen Y. Four decades of necrotizing sarcoid granulomatosis: what do we know now? Arch Pathol Lab Med 2015; 139: 252-262.

Liebow AA. The J. Burns Amberson Lecture - pulmonary angiitis and granulomatosis. Am Rev Respir Dis 1973; 108: 1-18.

Myers JL. Bronchocentric granulomatosis. Disease or diagnosis? Chest 1989; 96: 3-4.

Katzenstein AL, Liebow AA, Friedman PJ. Bronchocentric granulomatosis, mucoid impaction, and hypersensitivity reactions to fungi. Am Rev Respir Dis 1975; 111: 497-537.

Ward S, Heyneman LE, Flint JD, et al. Bronchocentric granulomatosis: computed tomographic findings in five patients. Clin Radiol 2000; 55: 296-300.

Robinson RG, Wehunt WD, Tsou E, et al. Bronchocentric granulomatosis: roentgenographic manifestations. Am Rev Respir Dis 1982; 125: 751-756.

Hurwitz LM, McAdams HP, Sporn TA. A 73-year-old woman with a cough. Chest 2005; 128: 1018-1021. 31-36.

Al-Binali AM, Scott B, Al-Garni A, et al. Granulomatous pulmonary disease in a child: an unusual presentation of Crohn's disease. Pediatr Pulmonol 2003; 36: 76-80.

Casey MB, Tazelaar HD, Myers JL, et al. Noninfectious lung pathology in patients with Crohn's disease. Am J Surg Pathol 2003; 27: 213-219.

Costabel U, Bonella F, Guzman J. Chronic hypersensitivity pneumonitis. Clin Chest Med 2012; 33: $151-163$.

Lacasse Y, Girard M, Cormier Y. Recent advances in hypersensitivity pneumonitis. Chest 2012; 142: $208-217$.

Ohtani Y, Saiki S, Kitaichi M, et al. Chronic bird fancier's lung: histopathological and clinical correlation. An application of the 2002 ATS/ERS consensus classification of the idiopathic interstitial pneumonias. Thorax 2005; 60: 665-671.

Blanchet MR, Israel-Assayag E, Cormier Y. Inhibitory effect of nicotine on experimental hypersensitivity pneumonitis in vivo and in vitro. Am J Respir Crit Care Med 2004; 169: 903-909.

Lacasse Y, Selman M, Costabel U, et al. Clinical diagnosis of hypersensitivity pneumonitis. Am J Respir Crit Care Med 2003; 168: 952-958.

Selman M, Pardo A, King TE Jr. Hypersensitivity pneumonitis: insights in diagnosis and pathobiology. Am J Respir Crit Care Med 2012; 186: 314-324.

Lynch DA, Rose CS, Way D, et al. Hypersensitivity pneumonitis: sensitivity of high-resolution CT in a population-based study. Am J Roentgenol 1992; 159: 469-472.

Tateishi T, Ohtani Y, Takemura T, et al. Serial high-resolution computed tomography findings of acute and chronic hypersensitivity pneumonitis induced by avian antigen. J Comput Assist Tomogr 2011; 35: 272-279.

Patel RA, Sellami D, Gotway MB, et al. Hypersensitivity pneumonitis: patterns on high-resolution CT. J Comput Assist Tomogr 2000; 24: 965-970.

Adler BD, Padley SP, Muller NL, et al. Chronic hypersensitivity pneumonitis: high-resolution CT and radiographic features in 16 patients. Radiology 1992; 185: 91-95.

Remy-Jardin M, Remy J, Wallaert B, et al. Subacute and chronic bird breeder hypersensitivity pneumonitis: sequential evaluation with CT and correlation with lung function tests and bronchoalveolar lavage. Radiology 1993; 189: 111-118.

Erkinjuntti-Pekkanen R, Rytkonen H, Kokkarinen JI, et al. Long-term risk of emphysema in patients with farmer's lung and matched control farmers. Am J Respir Crit Care Med 1998; 158: 662-665.

Cormier Y, Brown M, Worthy S, et al. High-resolution computed tomographic characteristics in acute farmer's lung and in its follow-up. Eur Respir J 2000; 16: 56-60.

Hansell DM, Wells AU, Padley SP, et al. Hypersensitivity pneumonitis: correlation of individual CT patterns with functional abnormalities. Radiology 1996; 199: 123-128.

Silva CI, Muller NL, Lynch DA, et al. Chronic hypersensitivity pneumonitis: differentiation from idiopathic pulmonary fibrosis and nonspecific interstitial pneumonia by using thin-section CT. Radiology 2008; 246: 288-297.

Jeong YJ, Lee KS, Chung MP, et al. Chronic hypersensitivity pneumonitis and pulmonary sarcoidosis: differentiation from usual interstitial pneumonia using high-resolution computed tomography. Semin Ultrasound CT MR 2014; 35: 47-58.

Walsh SL, Sverzellati N, Devaraj A, et al. Chronic hypersensitivity pneumonitis: high resolution computed tomography patterns and pulmonary function indices as prognostic determinants. Eur Radiol 2012; 22: $1672-1679$.

02 Lynch DA, Newell JD, Logan PM, et al. Can CT distinguish hypersensitivity pneumonitis from idiopathic pulmonary fibrosis? Am J Roentgenol 1995; 165: 807-811.

Semenzato G, Bjermer L, Costabel U, et al. Clinical guidelines and indications for bronchoalveolar lavage (BAL): extrinsic allergic alveolitis. Eur Respir J 1990; 3: 945-946.

Ohshimo S, Bonella F, Cui A, et al. Significance of bronchoalveolar lavage for the diagnosis of idiopathic pulmonary fibrosis. Am J Respir Crit Care Med 2009; 179: 1043-1047.

Meyer KC, Raghu G, Baughman RP, et al. An official American Thoracic Society clinical practice guideline: the clinical utility of bronchoalveolar lavage cellular analysis in interstitial lung disease. Am J Respir Crit Care Med 2012; 185: 1004-1014.

Costabel U. The alveolitis of hypersensitivity pneumonitis. Eur Respir J 1988; 1: 5-9.

Drent M, van Velzen-Blad H, Diamant M, et al. Bronchoalveolar lavage in extrinsic allergic alveolitis: effect of time elapsed since antigen exposure. Eur Respir J 1993; 6: 1276-1281.

Drent M, Wagenaar S, van Velzen-Blad H, et al. Relationship between plasma cell levels and profile of bronchoalveolar lavage fluid in patients with subacute extrinsic allergic alveolitis. Thorax 1993; 48: 835-839. 
Groot Kormelink T, Pardo A, Knipping K, et al. Immunoglobulin free light chains are increased in hypersensitivity pneumonitis and idiopathic pulmonary fibrosis. PLoS One 2011; 6: e25392.

Costabel U, Bross KJ, Ruhle KH, et al. Ia-like antigens on T-cells and their subpopulations in pulmonary sarcoidosis and in hypersensitivity pneumonitis. Analysis of bronchoalveolar and blood lymphocytes. Am Rev Respir Dis 1985; 131: 337-342. S64-S66.

Tondell A, Ro AD, Borset M, et al. Activated $\mathrm{CD}^{+} \mathrm{T}$ cells and natural killer $\mathrm{T}$ cells in bronchoalveolar lavage fluid in hypersensitivity pneumonitis and sarcoidosis. Sarcoidosis Vasc Diffuse Lung Dis 2015; 31: 316-324.

Cai M, Bonella F, He X, et al. CCL18 in serum, BAL fluid and alveolar macrophage culture supernatant in interstitial lung diseases. Respir Med 2013; 107: 1444-1452.

Vasakova M, Sterclova M, Kolesar L, et al. Cytokine gene polymorphisms and BALF cytokine levels in interstitial lung diseases. Respir Med 2009; 103: 773-779.

Falfán-Valencia R, Camarena A, Pineda CL, et al. Genetic susceptibility to multicase hypersensitivity pneumonitis is associated with the TNF-238 GG genotype of the promoter region and HLA-DRB ${ }^{\star} 04$ bearing HLA haplotypes. Respir Med 2014; 108: 211-217.

Camarena A, Aquino-Galvez A, Falfan-Valencia R, et al. PSMB8 (LMP7) but not PSMB9 (LMP2) gene polymorphisms are associated to pigeon breeder's hypersensitivity pneumonitis. Respir Med 2010; 104: 889-894

Khoor A, Leslie KO, Tazelaar HD, et al. Diffuse pulmonary disease caused by nontuberculous mycobacteria in immunocompetent people (hot tub lung). Am J Clin Pathol 2001; 115: 755-762.

Ganesan S, Felo J, Saldana M, et al. Embolized crospovidone (poly[N-vinyl-2-pyrrolidone]) in the lungs of intravenous drug users. Mod Pathol 2003; 16: 286-292.

Jennette JC, Falk RJ, Bacon PA, et al. 2012 revised International Chapel Hill Consensus Conference Nomenclature of Vasculitides. Arthritis Rheum 2013; 65: 1-11.

Kallenberg CG, Mulder AH, Tervaert JW. Antineutrophil cytoplasmic antibodies: a still-growing class of autoantibodies in inflammatory disorders. Am J Med 1992; 93: 675-682.

Cabral DA, Canter DL, Muscal E, et al. Comparing presenting clinical features in 48 children with microscopic polyangiitis to 183 children who have granulomatosis with polyangiitis (Wegener's): an ARChiVe cohort study. Arthritis Rheumatol 2016; 68: 2514-2526.

Nelson DR, Johnson GB, Cartin-Ceba R, et al. Characterization of F-18 fluorodeoxyglucose PET/CT in granulomatosis with polyangiitis. Sarcoidosis Vasc Diffuse Lung Dis 2016; 32: 342-352.

Merkel PA, Xie G, Monach PA, et al. Identification of functional and expression polymorphisms associated with risk for anti-neutrophil cytoplasmic autoantibody-associated vasculitis. Arthritis Rheumatol 2017; 69: 1054-1066.

Cottin V, Bel E, Bottero P, et al. Respiratory manifestations of eosinophilic granulomatosis with polyangiitis (Churg-Strauss). Eur Respir J 2016; 48: 1429-1441.

Martorana D, Bonatti F, Alberici F, et al. Fcgamma-receptor 3B (FCGR3B) copy number variations in patients with eosinophilic granulomatosis with polyangiitis. J Allergy Clin Immunol 2016; 137: 1597-1599.

Kovacs A, Baksay B, Cserenyecz A, et al. Occurrence of pulmonary rheumatoid nodules following biologica therapies. Clin Rheumatol 2015; 34: 1639-1642.

Churg A. Pulmonary angiitis and granulomatosis revisited. Hum Pathol 1983; 14: 868-883.

Tazi A. Adult pulmonary Langerhans' cell histiocytosis. Eur Respir J 2006; 27: 1272-1285.

Suri HS, Yi ES, Nowakowski GS, et al. Pulmonary Langerhans cell histiocytosis. Orphanet J Rare Dis 2012; $7: 16$.

DeMartino E, Go RS, Vassallo R. Langerhans cell histiocytosis and other histiocytic diseases of the lung. Clin Chest Med 2016; 37: 421-430.

Kulwiec EL, Lynch DA, Aguayo SM, et al. Imaging of pulmonary histiocytosis X. Radiographics 1992; 12: 515-526.

Kim HJ, Brown MS, Elashoff R, et al. Quantitative texture-based assessment of one-year changes in fibrotic reticular patterns on HRCT in scleroderma lung disease treated with oral cyclophosphamide. Eur Radiol 2011; 21: $2455-2465$.

Housini I, Tomashefski JF Jr, Cohen A, et al. Transbronchial biopsy in patients with pulmonary eosinophilic granuloma. Comparison with findings on open lung biopsy. Arch Pathol Lab Med 1994; 118: 523-530.

Krajicek BJ, Ryu JH, Hartman TE, et al. Abnormal fluorodeoxyglucose PET in pulmonary Langerhans cell histiocytosis. Chest 2009; 135: 1542-1549.

Obert J, Vercellino L, Van Der Gucht A, et al. ${ }^{18}$ F-fluorodeoxyglucose positron emission tomography-computed tomography in the management of adult multisystem Langerhans cell histiocytosis. Eur J Nucl Med Mol Imaging 2017; 44: 598-610.

Cunningham-Rundles C, Bodian C. Common variable immunodeficiency: clinical and immunological features of 248 patients. Clin Immunol 1999; 92: 34-48.

Hurst JR, Verma N, Lowe D, et al. British Lung Foundation/United Kingdom Primary Immunodeficiency Network Consensus Statement on the Definition, Diagnosis, and Management of Granulomatous-Lymphocytic Interstitial Lung Disease in Common Variable Immunodeficiency Disorders. J Allergy Clin Immunol Pract 2017; in press [https://doi.org/10.1016/j.jaip.2017.01.021].

Mechanic LJ, Dikman S, Cunningham-Rundles C. Granulomatous disease in common variable immunodeficiency. Ann Intern Med 1997; 127: 613-617.

Jolles S, Carne E, Brouns M, et al. FDG PET-CT imaging of therapeutic response in granulomatous lymphocytic interstitial lung disease (GLILD) in common variable immunodeficiency (CVID). Clin Exp Immunol 2017; 187: 138-145.

Mukhopadhyay S, Katzenstein AL. Pulmonary disease due to aspiration of food and other particulate matter: clinicopathologic study of 59 cases diagnosed on biopsy or resection specimens. Am J Surg Pathol 2007; 31: $752-759$. 